\title{
Lower Respiratory Tract Tumours in Syrian Golden Hamsters after Intratracheal Instillations of Diethylnitrosamine alone and with Ferric Oxide*
}

\author{
V. J. FERON $\dagger$, P. EMMELOT $\ddagger$ and T. VOSSENAAR $\S$
}

$\dagger$ Central Institute for Nutrition and Food Research TNO, Zeist, $¥$ Antoni van Leeuwenhoek-Huis, The Netherlands Cancer Institute, Amsterdam and §Department of Pathology, State University of Utrecht, Utrecht, The Netherlands

\begin{abstract}
A total of 37 tumours of the lower respiratory tract (bronchi, bronchioli and alveoli) was observed in 62 male and female Syrian golden hamsters following 15 weekly intratracheal instillations of diethylnitrosamine (DENA) alone. The number of tumours in this segment of the respiratory system was 3 times higher when ferric oxide was administered simultaneously with DENA (107 neoplasms in a total of 62 animals examined). The neoplastic response of the lower respiratory tract mainly consisted of adenomas in the bronchiolo-alveolar region, although bronchial papillomas and a few peripheral carcinomas were also observed.

The well-known, marked carcinogenic effect of DENA on the upper respiratory tract of the Syrian golden hamster was confirmed.
\end{abstract}

\section{INTRODUCTION}

IN SYRIAN golden hamsters the respiratory tract is the main target organ for the carcinogenic action of diethylnitrosamine (DENA) irrespective of the route of administration [1-8]. The tumour response to DENA, however, appears to vary considerably in the different segments of the respiratory tract. In general, the broncho-alveolar system of the hamster is less susceptible to the carcinogenic action of DENA than the upper respiratory tract is $[3-5,7-9]$.

Ferric oxide (haematite) has been extensively tested for possible carcinogenic activity, but always with negative results [9-11]. In experimental respiratory carcinogenesis ferric oxide

Accepted 1 March 1972.

*This work was supported by a grant from the research fund of the Scientific Advisory Committee Smoking and Health. This fund has been established by the Dutch Gigarette Industry Foundation. has been introduced as a carrier for particles of carcinogenic chemicals. Intratracheal instillation of such mixtures appeared an effective method for the induction of respiratory tumours in hamsters [11]. The essential property of the ferric oxide particles has been considered their capacity to facilitate the penetration and retention of the carcinogen in the lung tissue. However, this explanation does not cover observations of Montesano et al. [7, 9 , 12] that subcutaneous treatment of hamsters with DENA, followed by intratracheal instillation of ferric oxide resulted in a much higher incidence of broncho-alveolar tumours than DENA treatment alone did. Moreover, in a recent report Harris et al. [13] mentioned that ferric oxide may act as a cofactor in respiratory carcinogenesis, because they observed a marked basal cell hyperplasia of the tracheobronchial epithelium in hamsters when multiple doses of ferric oxide were administered intratracheally. 
In the present experiment the role of ferric oxide in pulmonary carcinogenesis was investigated by comparing the effect of intratracheal instillation of ferric oxide and DENA, either alone or in combination.

\section{MATERIAL AND METHODS}

\section{Materials}

Diethylnitrosamine (DENA) was obtained from EGA-Chemie K.G., Keppler and Reif, Steinheim/Albuch, W. Germany. Its purity was checked by gas-liquid chromatography. Ferric oxide (haematite, particle size distribution: $99 \%<5 \mu \mathrm{m}, \quad 98 \%<3 \mu \mathrm{m}, \quad 95 \%<1 \mu \mathrm{m}$ ) was obtained from Fisher Scientific Co., Fair Lawn, N.J., U.S.A., and the saline solution $(0.9 \%$ sodium chloride, sterile, non-pyrogenic) from Baxter Laboratories, A. Christiaens N.V., Brussels, Belgium. A $1.5 \%$ solution of DENA in saline $(\mathrm{v} / \mathrm{v})$ and a $1.5 \%$ ferric oxide suspension in saline or in $1.5 \%$ DENA $(\mathrm{w} / \mathrm{v})$ were prepared and stored at $4^{\circ} \mathrm{C}$ (maximally 4 weeks) in quantities sufficient for 1 instillation of all hamsters in a certain group.

\section{Animals}

Syrian golden hamsters, obtained from the Central Institute for the Breeding of Laboratory Animals TNO, Zeist, The Netherlands, were separated by sex and housed in sets of 5 in screen-bottom cages in a temperature-controlled room at 24 to $26^{\circ} \mathrm{C}$. The animals were fed a pelleted stock diet (Muracon I, Trouw \& Co., N.V., Amsterdam-Putten, The Netherlands) and tap water ad libitum. The hamsters were about 11 weeks old when the experiment was started.

\section{Experimental design and conduct}

Four groups of hamsters, each consisting of 35 males and 35 females, received a course of 15 weekly intratracheal instillations. For the various groups each instillation consisted of $0.2 \mathrm{ml}$ saline, $3 \mathrm{mg}$ ferric oxide suspended in $0.2 \mathrm{ml}$ saline, $0.2 \mathrm{ml} 1.5 \%$ DENA in saline or $3 \mathrm{mg}$ ferric oxide suspended in $0.2 \mathrm{ml} 1.5 \%$ DENA in saline. Before each treatment the animals were lightly anaesthetized with freshly distilled ether. The instillation procedure was not essentially different from the one used by Saffiotti et al. [11]. At the end of the treatment period (week 15) 3 males and 3 females out of each group were sacrificed for pathological examination. The experiment was terminated after 78 weeks. Hamsters that died spontaneously or were killed when moribund were autopsied. For killing the animals, and removing and processing the lungs, the technique described in detail by Saffiotti et al. [11] was used. Following fixation in $10 \%$ neutral formalin, the head (after decalcification of the skull in nitric acid), larynx, trachea, pulmonary lobes, liver, kidneys and other organs showing gross pathology were embedded in paraffin, sectioned (larynx, trachea and pulmonary lobes at 3 levels) and stained with haematoxylin-eosin and other stains when required.

\section{RESULTS}

\section{Mortality and body weights}

Hamsters treated with DENA or DENA plus ferric oxide showed a much higher mortality and significantly lower body weights than did saline treated controls (Fig. 1). Ferric oxide treatment affected neither survival rates nor body weights. Death in animals given DENA or DENA plus ferric oxide was almost exclusively due to asphyxia resulting from obstruction of the tracheal lumen by papillomas.

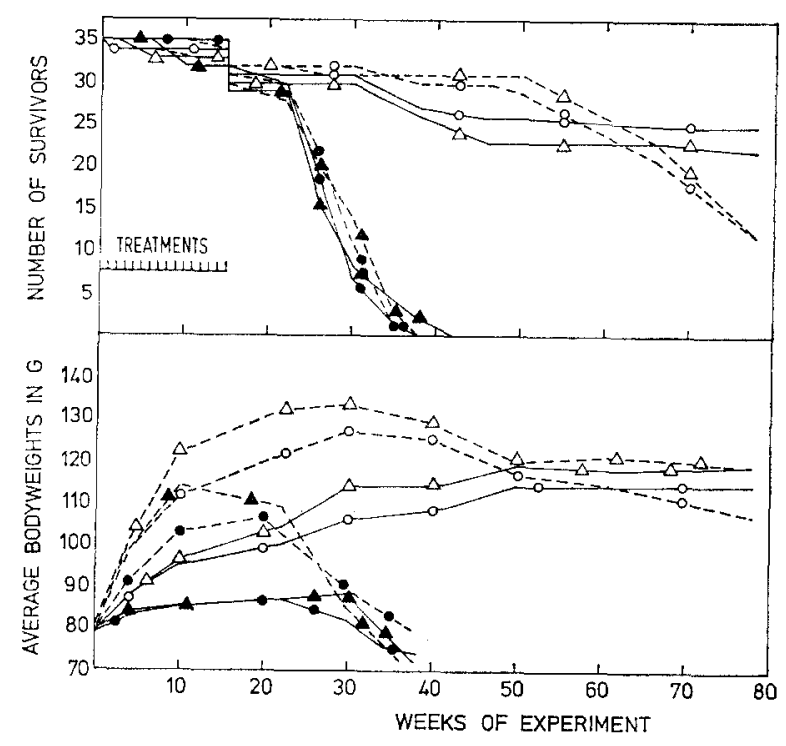

Fig. 1. Survival rates and average body weights of male (-) and female(--) Syrian golden hamsters treated intratracheally with saline $(\triangle)$, ferric oxide (O), DENA $(\triangle)$ or DENA plus ferric oxide (). At the end of the treatment period 3 males and 3 females of each group were killed for interim information.

\section{Tumours of the lower respiratory tract}

Small papillomas of the main-stem bronchi were observed in 4 males treated with DENA alone and in 11 hamsters given DENA plus ferric oxide (Table 1).

Single or multiple adenomas in the bronchiolo-alveolar region (Figs. 2-5) were observed in 21 hamsters treated with DENA alone and in 


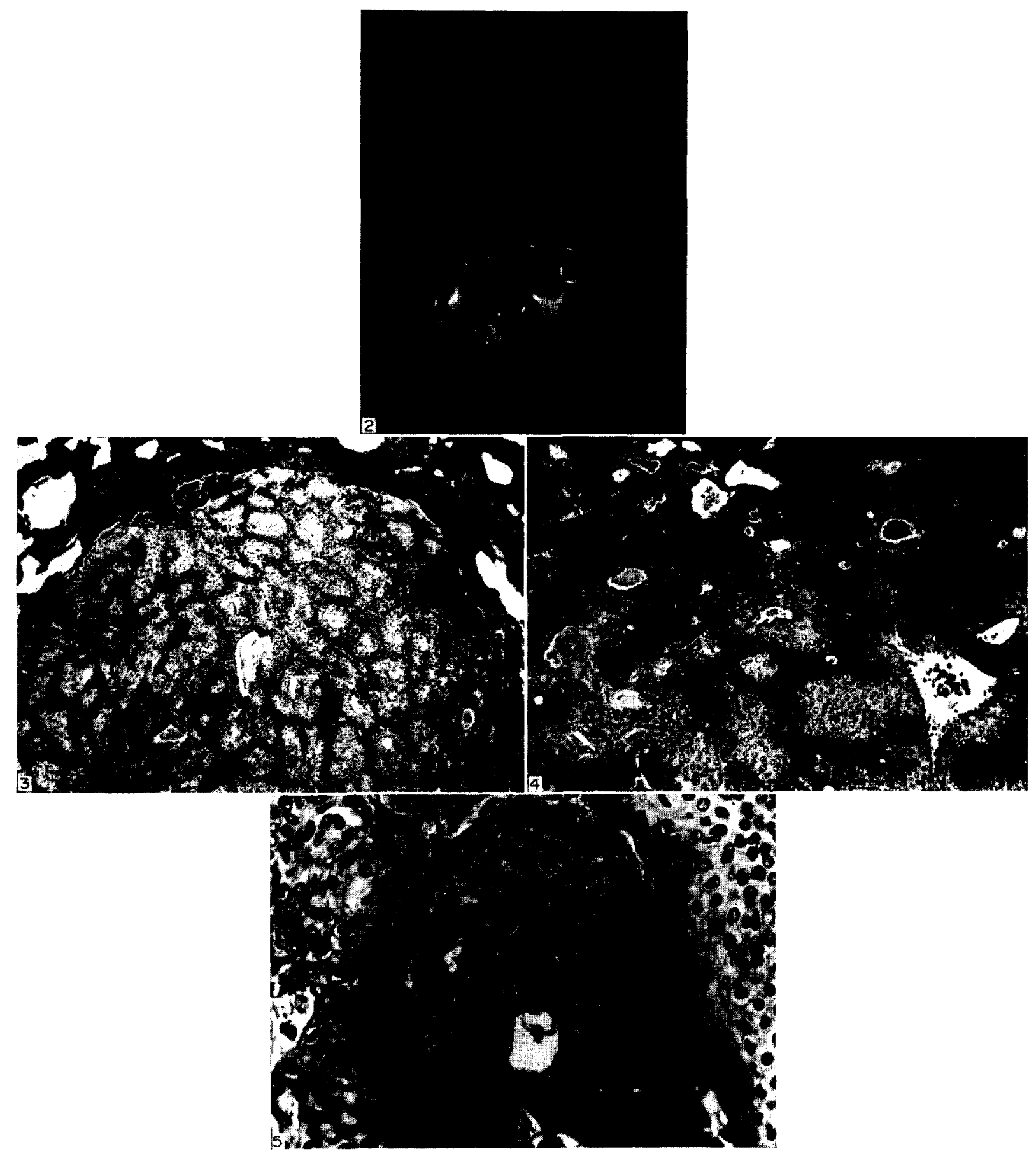

Fig. 2. DENA-induced peripheral lung tumours.

Fig. 3. Peripheral pulmonary adenoma. Adenomatous structures lined by stratified squamous-like epithelium. Note the massive amounts of ferric oxide in the pulmonary tissue adjacent to the tumour (DENA plus ferric oxide, Kreyberg's stain, $\times 56$ ).

Fig. 4. Characteristic appearance of DENA-induced pulmonary adenoma (DENA plus ferric oxide, Kreyberg's stain $\times 140$ ).

Fig. 5. Pulmonary adenoma. A few mucin-producing cells (alcian green positive; arrows) are visible (DENA, Kreyberg's stain, $\times 370$ ). 
Table 1. Type and incidence of tumours of the lower respiratory tract in Syrian golden hamsters given a course of 15 weekly intratracheal instillations of saline, ferric oxide, DENA or DENA plus ferric oxide.

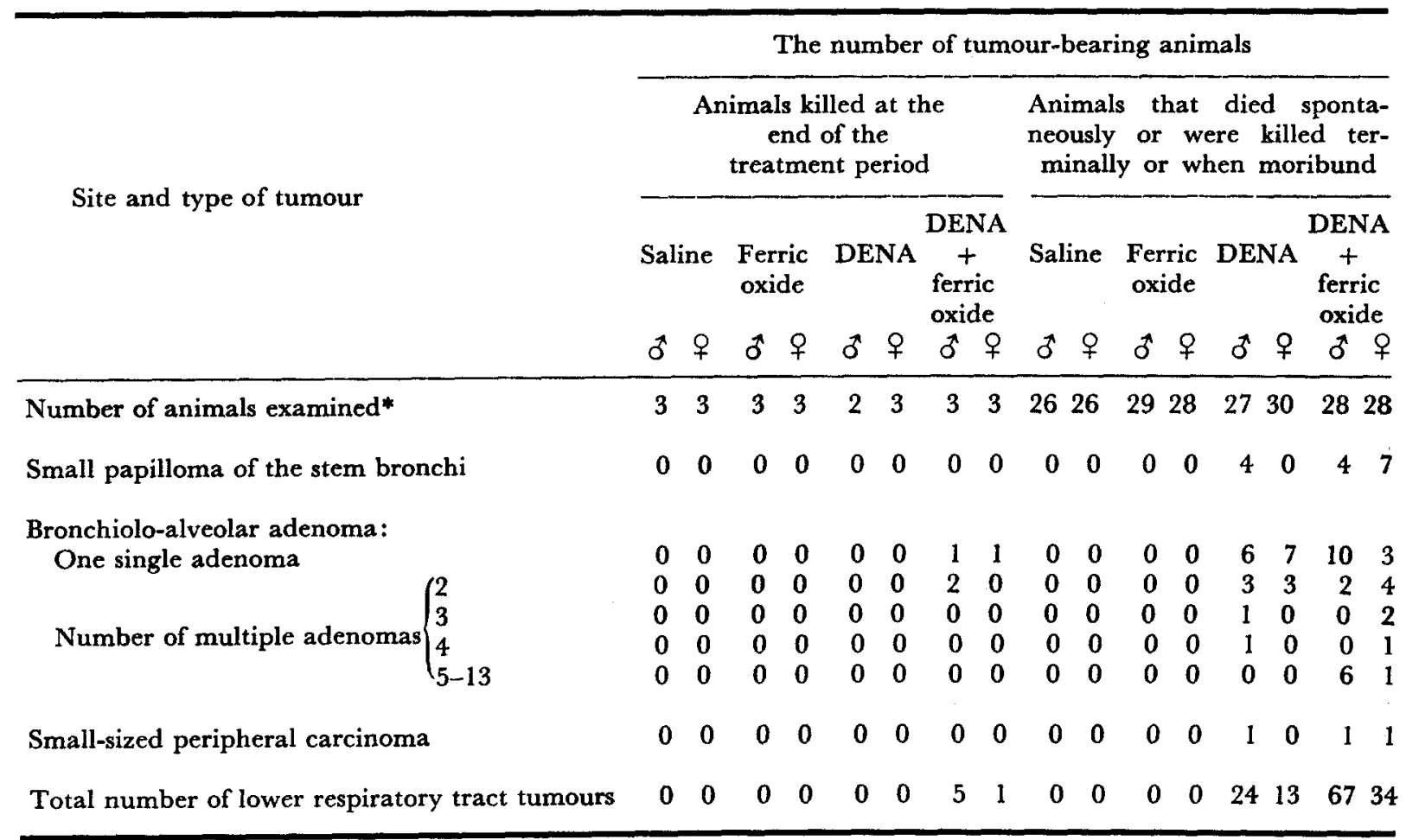

*Initially, each group consisted of 35 male and 35 female hamsters.

33 which had received DENA plus ferric oxide. The total number of bronchiolo-alveolar adenomas in the DENA-group was 32 and that in the DENA plus ferric oxide-group was as high as 94. Of the 6 animals of each group killed at the end of the treatment period, 4 treated with DENA plus ferric oxide had already developed such adenomas, whereas in the animals of the other groups these tumours were not found at all at this time.

Grossly, the adenomas appeared as greyishwhite, firm nodules measuring $0 \cdot 1$ to $1 \mathrm{~cm}$ in diameter (Fig. 2). Microscopically, they appeared to consist predominantly of acinar structures lined by stratified, squamous-like epithelium (Figs. 3, 4). The cells were round to oval and rather uniform, had distinct cell boundaries and moderate amounts of pale cytoplasm (Figs. 4, 5). Superficial cell layers were often flattened, but keratinization was never seen. Intercellular bridges could not be identified unequivocally. The cytoplasm of an occasional superficial tumour cell contained alcian green positive material, indicating mucin formation (Fig. 5). Several of the larger neoplasms had a wide central lumen, surrounded by clusters of the adenomatous structures described. Columnar epithelium was encountered in a few tumours. Transition from this type of epithelium to stratified epithelium was sometimes visible. The tumours invariably were circumscript.

Three small-sized peripheral tumours, showing characteristics of squamous cell or anaplastic large cell carcinomas, were found among DENA or DENA plus ferric oxide treated animals.

In addition to the tumours in the bronchoalveolar system, marked cellular and nuclear atypism and areas of atypical hyperplasia were noticed in the bronchial lining epithelium of all animals given DENA or DFNA plus ferric oxide, but in none of the saline- or ferric oxide-treated hamsters. Degree and frequency of these changes were comparable in both treatment groups.

Peribronchiolar adenomatoid lesions of a minimal extension were seen mostly in ferric oxide-treated animals which survived the experimental period, but occurred also in a few animals of each of the other groups.

A few small patches of alveolar mucous cell metaplasia were found in 1 or 2 hamsters of the various groups, including the saline-treated control group.

\section{Tumours of the upper respiratory tract}

Many tumours of the nasal cavity $(36 \%)$, moderate numbers of laryngeal papillomas. 
$(7 \%)$ and a nearly $100 \%$ incidence of tracheal papillomas were noticed in hamsters treated with DENA or DENA plus ferric oxide. There was no distinct difference in incidence of these tumours between both groups. The morphology of these upper respiratory tract tumours was the same as described previously $[4,5,7]$, except for the presence of squamous epithelium in tracheal papillomas which could not be identified unequivocally in the present material. The latter observation is in agreement with recent ultrastructural work on DENA-induced tracheal papillomas in hamsters, the results of which did not give evidence of metaplastic change to squamous epithelium in these tumours [14, 15].

\section{Other tumours}

In the liver 4 hepatocellular carcinomas and one cholangioma were observed in 3 males and 1 female treated with DENA plus ferric oxide. In addition, the following tumours, unrelated to DENA-treatment, were found: 1 thyroid adenoma, 2 adrenal cortical adenomas, 1 sarcomatous tumour and 1 ovarian tumour.

\section{DISCUSSION}

The results of this experiment confirm the finding of other investigators that DENA has a marked carcinogenic effect on the upper respiratory tract of the Syrian golden hamster [3-9]. With regard to type and incidence of DENA-induced tumours in the lower respiratory tract of the hamster, some discrepancies are noticeable in the literature as has been discussed in detail by Montesano and Saffiotti [7]. The neoplastic response of the lower respiratory tract to DENA alone, observed in the present study, was less than that obtained by Dontenwill et al. $[1,2]$, but higher than that reported by the other authors [3, 5-8]. Our findings, however, seem to be in keeping with a recent statement by Montesano et al. [9] that Dontenwill had repeated his previous experiments with DENA in hamsters [1,2] and now observed much lower incidences of tumours of the broncho-alveolar system. Moreover, when Montesano et al. [9] administered the maximal tolerated dose of DENA to adult hamsters, they found a higher incidence of tumours in the lower respiratory tract than in their former experiments [9].

The neoplastic response of the lower respiratory tract in our hamsters mainly consisted of benign tumours considered to be derived from the bronchiolo-alveolar system and showing adenomatous structures predominantly lined by stratified epithelium. The histological appearance of these tumours resembles that of the benign peripheral adeno-squamous neoplasms or bronchiolar "papillomas" reported previously in hamsters after treatment with various carcinogens $[9,10,12]$.

In comparison with the results of DENAtreatment alone, those obtained after the concurrent intratracheal instillation of DENA and ferric oxide were indicative of a shortening of the latent period of bronchiolo-alveolar adenomas and showed a marked increase in the tumour yield of the lower respiratory tract. This finding is in keeping with the observation of Montesano et al. [9] that subcutaneous treatment of Syrian golden hamsters with DENA followed, 5 weeks later, by intratracheal instillation of ferric oxide resulted in a much higher incidence of broncho-alveolar tumours than DENA-treatment alone did. Ferric oxide, therefore, might be considered a cocarcinogen.

As tracheal papillomas in DENA-treated hamsters developed relatively early, the high incidence of pulmonary tumours in these animals could be due to transplantation of the tracheal papillomas into the lower respiratory tract as a consequence of the instillation procedure. The presence of ferric oxide particles may facilitate the transplantation and explain the increased incidence of lung tumours in animals treated with DENA plus ferric oxide. In this connection the morphology of the lung tumours is very interesting and, therefore, electron microscopical studies on this type of DENA-induced tumours have meanwhile been undertaken. The results obtained so far, are indicative of alveolar cell origin of these pulmonary neoplasms [16].

Acknowledgements-Thanks are due to Dr. A. P. de Groot for helpful discussions and critically reviewing the manuscript, and to Miss A. Wierda, Miss S. van Loenen, Miss G. Jansen and Messrs. D. T. de Jong, H. Koëter, H. Immel and G. Roverts for competent technical assistance.

\section{REFERENCES}

1. W. Dontenwill and U. Mohr, Carcinome des Respirationstractus nach Behandlung von Goldhamstern mit Diäthylnitrosamin. Z. Krebsforsch. 64, 305 (1961). 
2. W. DonTenwiLl, U.Mohr and M. ZAGEL, Ueber die unterschiedliche Lungencarcinogene Wirkung des Diäthylnitrosamin bei Hamster und Ratte. $Z$. Krebsforsch. 64, 499 (1962).

3. K. M. Herrold and L. J. Dunham, Induction of tumors in the Syrian hamster with diethylnitrosamine (N-nitrosodiethylamine). Cancer Res. 23, 773 (1963).

4. K. M. Herrold, Epithelial papillomas of the nasal cavity: Experimental induction in Syrian hamsters. Arch. Path. 78, 189 (1964).

5. K. M. Herrold, Effect of route of administration on the carcinogenic action of diethylnitrosamine (N-nitrosodietylamine). Brit. J. Cancer 18, 763 (1964).

6. U. Mohr, O. Wieser and K. Pielsticker, Die Minimaldosis für die Wirkung von Diäthylnitrosamin auf die Trachea beim Goldhamster. Naturwissenschaften 53, 229 (1966).

7. R. Montesano and U. SAfFiotti, Carcinogenic response of the respiratory tract of Syrian golden hamsters to different doses of diethylnitrosamine. Cancer Res. 28, 2197 (1968).

8. R. Montesano and U. Saffiottr, Carcinogenic response of the hamster respiratory tract to single subcutaneous administrations of diethylnitrosamine at birth. J. Nat. Cancer Inst. 44, 413 (1970).

9. R. Montesano, U. Saffiotti and P. Shubik, The role of topical and systemic factors in experimental respiratory carcinogenesis. In Inhalation Carcinogenesis (edited by M. G. Hanna, P. Netteshetm and J. R. Gilbert). Proc. Biol. Div., Oak Ridge Natl Lab., U.S. Atomic Energy Comm., Conf. 691001, p. 353, Catlinburg (1970).

10. U. SAFFIOTt, F. CEFIS and P. SHUBIK, Histopathology and histogenesis of lung cancer induced in hamsters by carcinogens carried by dust particles. In Lung Tumours in Animals (edited by L. Severr). Proc. 3rd Quadrennial Int. Conf. Cancer, p. 537, Perugia (1966).

11. U. Saffiotti, F. Cefis and L. H. Kolb, A method for the experimental induction of bronchogenic carcinoma. Cancer Res. 28, 104 (1968).

12. R. Montesano, Systemic carcinogens (N-nitroso compounds) and synergistic or additive effects in respiratory carcinogenesis. Tumori 56, 335 (1970).

13. C. C. HARRis, J.M. Smith, M.B. Sporn and U. SAFFiotti, Acute ultrastructural effects of benzo(a)pyrene on the hamster respiratory epithelium. Proc. Amer. Ass. Cancer Res. 12, 13 (1971).

14. J. Althoff and R. Wilson, Observations of the respiratory epithelium of DEN-treated Syrian golden hamsters. Proc. Amer. Ass. Cancer. Res. 12, 103 (1971).

15. J. Althoff, R. Wilson and U. Mohr, Diethylnitrosamine-induced alterations in the tracheobronchial system of Syrian golden hamsters. J. Nat. Cancer Inst. 46, 1067 (1971).

16. W. Straks and V. J. Feron, Unpublished observations. 